\title{
FORMULASI KONSEP MODERASI ISLAM BERBASIS KEINDONESIAAN DALAM MEREDUKSI RADIKALISME AGAMA DI INDONESIA (KAJIAN EPISTEMOLOGIS-HISTORIS)
}

\author{
M. Mucharom syifa \\ Institut Agama Islam Negeri Pekalongan \\ data.syifa2@gmail.com
}

\begin{abstract}
The religious phenomenon of Islam in post-reform Indonesia is thought to have experienced extremism and radicalism. The explosion of terrorism in the name of Islam that occurred between 1998 and 2018 made the face of Indonesian Islam in the world. Whereas in fact Islam in Indonesia is Islam that promotes moderate principles (tawassuth / washatiah) in preaching, namely taking a middle ground between the opposite two extreme poles. Da'wah method of Washatiyatul Islam or Moderation of Islam is a method of da'wah that emphasizes the Islamic values of Rahmatan Lil Alamin. Da'wah is friendly with tradition, so it can grow in a multicultural and multi-religious society. It is this characteristic of accommodative Islam that is the stronghold of the prevention of radical religious ideas. This article using the epistemological-historical-holisitic approach wants to explore the concept of moderation of Islam in the context of the Indonesian nation and the shallowness of religious reasoning. As a result, none of the strong references say that the spread of Islam in ancient Archipelago was by radical means. The history of Islam in the archipelago has struggled with diverse localities. Islam is not present to break down or chop away existing traditions and local culture, but try to dialect with the context in which Islam is located. Because of its flexible nature, Islam is able to survive and develop so that it raises a new Islamic style that is unique and does not exist in any part of the world.
\end{abstract}

Keywords: Moderation of Islam, Integration-Interconnection, Nationality Jurisprudence, Radicalism, Islam rahmatan lil alamin.

\begin{abstract}
ABSTRAK
Fenomena keagamaan islam di Indonesia pasca reformasi ditengarai banyak mengalami ekstrimisme dan radikalisme. Ledakan terorisme atas nama Islam yang terjadi antara tahun 1998 hingga 2018 menjadikan wajah Islam Indonesia mendapat sorotan di dunia. Padahal sejatinya Islam yang ada di Indonesia adalah Islam yang mengedepankan prinsip moderat (tawassuth/washatiah) dalam berdakwah, yaitu mengambil jalan tengah di antara dua kutub ekstrim yang berlawanan. Metode dakwah Washatiyatul Islam atau Moderasi Islam adalah metode dakwah yang mengedepankan nilai-nilai Islam Rahmatan Lil Alamin. Dakwah yang ramah dengan tradisi,
\end{abstract}


sehingga dapat tumbuh dalam masyarakat yang multikultultural dan multireligi. Karakteristik Islam akomodatif inilah yang menjadi benteng pencegahan faham keagaamaan radikal. Artikel ini dengan menggunakan pendekatan epistemologis-historis-holisitik ingin menelisik konsep moderasi Islam dalam konteks bangsa Indonesia dan kedangkalan nalar beragama. Hasilnya, tak ada satupun referensi kuat yang mengatakan bahwa penyebaran Islam di Nusantara zaman dahulu adalah dengan caracara radikal. Sejarah Islam di Nusantara telah mengalami pergumulan dengan lokalitas yang beragam. Islam hadir bukan untuk mendobrak atau membabat habis tradisi dan budaya lokal yang ada, melainkan mencoba untuk berdialektika dengan konteks di mana Islam berada. Oleh karena sifat fleksibelnya itu, Islam mampu bertahan dan berkembang sehingga memunculkan corak keislaman baru yang khas dan tidak ada di belahan dunia manapun.

Kata Kunci: Moderasi Islam, Integrasi-Interkoneksi, Fiqih Kebangsaan, Radikalisme, Islam rahmatan lil alamin.

\section{Pendahuluan}

Secara historis kedatangan Islam di Indonesia dilakukan secara damai, dimana Islam pertama kali masuk melalui wilayah pesisir hingga ke pedalaman yang penyebaran Islam di ambil alih dan dilaksanakan oleh para ulama. ${ }^{1}$ Hal tersebut tentunya berbeda dengan penyebaran Islam di Timur Tengah yang beberapa kasus disertai dengan penundukan wilayah oleh militer muslim. ${ }^{2}$ Secara perlahan dan bertahap, tanpa menolak keras, terhadap sosio-kultural masyarakat sekitar, Islam memperkenalkan toleransi dan persamaan derajat. Inilah yang menjadikan masyarakat Hindu-Jawa menjadi tertarik dengan Islam, karena ajaran tersebut sejalan dengan mereka, yaitu hidup rukun berdampingan tanpa kekerasan. ${ }^{3}$ Hal ini dikarenakan penyebaran Islam tidak melalui fututh, melainkan diperkenalkan oleh para penyebar Islam dengan cara akulturasi ajaran Islam dengan budaya setempat yang kemudian menghasilkan kombinasi yang baik, sehingga menampilkan wajah Islam yang ramah dan moderat, atau bisa disebut sebagai the least Arabicized (paling kurang mengalami "Arabisasi). ${ }^{4}$ Penyebaran Islam ke wilayah Nusantara bisa kita lihat dari berbagai cara, yaitu melalui perdagangan, perkawinan, struktul sosial (mengislamkan raja-raja), pendidikan, tasawuf, serta seni dan budaya. ${ }^{5}$

Islam sebagai agama yang sempurna ${ }^{6}$, yaitu agama yang membawa rahmat bagi alam semesta (rahmatan lil alamin). Tentunya memiliki ajaran yang bersifat manusiawi dan universal. ${ }^{7}$ Namun pada masa modern ini, umat Islam Indonesia mengalami tantangan besar karena munculnya kelompok 
gerakan reformis yang berhaluan ekstrim, yaitu fundamentalisme dan, radikalisme. Hal tersebut ditunjukan oleh fakta mengenai pengeboman yang dilakukan oleh sekelompok teroris yang mengatasnamakan Islam, sehingga membuat wajah Islam di Indonesia dalam dua dasawarsa ini mendapatkan sorotan di berbagai belahan dunia. Padahal sejatinya Islam yang ada di Indonesia adalah Islam yang menggunakan prinsip moderat (tawasuth/washatiah), yaitu mengambil jalan tengah di antara dua kutub ekstrim yang berlawanan. Karakteristik islam akomodatif inilah yang menjadi benteng pencegahan faham keagaamaan yang radikal.

Berdasarkan fakta dan pemikiran di atas, maka menjadi penting dan relevan untuk dikaji secara mendalam dan komprehenseif dengan menggunakan pendekatan epistemologis-historis mengenai dinamika pemikiran moderasi Islam Indonesia; latar historis munculnya radikalisme agama di Indonesia dan; formulasi konsep moderasi Islam berbasis keindonesiaan yang memiiliki distingsi atau ciri khas baru, sehingga dapat memberikan solusi untuk mengatasi radikalisme agama di Indonesia.

\section{Dinamika pemikiran Moderasi Islam Indonesia}

Moderasi Islam berasal dari dua kata, yaitu Moderasi dan Islam. Kata Moderasi sendiri dalam KBBI Kemdikbud mempunyai arti pengurangan kekerasan. ${ }^{8}$ Kemudian kata Islam sendiri berasal dari bahasa arab aslamayuslimu-islaman, yang memilikiarti semantik tundukdan patuh. ${ }^{9}$ Sedangkan Moderasi Islam dalam bahasa arab disebut dengan al-Wasathiyyah alIslamiyyah. Al-Qaradawi menyebut beberapa kosakata yang serupa makna dengannya termasuk Tawazun, I'tidal, Ta'adul dan Istiqamah. Sementara dalam bahasa inggris sebagai Islamic Moderation. Moderasi Islam adalah sebuah pandangan atau sikap yang selalu berusaha mengambil posisi tengah dari dua sikap yang berseberangan dan berlebihan sehingga salah satu dari kedua sikap yang dimaksud tidak mendominasi dalam pikiran dan sikap seseorang. ${ }^{10}$

Dalam hal ini Islam adalah agama yang tidak memihak bentuk pemikiran individu, namun netral dalam berprinsip dan adil terhadap sesama, hal ini di bahas rinci dalam Al-Qur'an yang terdapat di dalam surat Al-Baqarah ayat 143 berikut ini, yang artinya :

"Dan demikian (pula) Kami telah menjadikan kamu (umat Islam), umat yang adil dan pilihan agar kamu menjadi saksi atas (perbuatan) manusia dan agar Rasul (Muhammad) menjadi saksi atas (perbuatan) kamu. Dan Kami tidak menetapkan kiblat yang menjadi kiblatmu (sekarang) melainkan agar Kami mengetahui (supaya nyata) siapa yang mengikuti 
Rasul dan siapa yang membelot. Dan sungguh (pemindahan kiblat) itu terasa amat berat, kecuali bagi orang-orang yang telah diberi petunjuk oleh Allah; dan Allah tidak akan menyia-nyiakan imanmu. Sesungguhnya Allah Maha Pengasih lagi Maha Penyayang kepada manusia."11

Baginda Nabi sendiri menafsiri kata أظََََ dalam firman Allah di atas dengan adil. Dimana kata adil berarti fair menempatkan sesuatu pada tempatnya. ${ }^{12}$ Tidak membeda-bedakan manusia dengan manusia lainnya. Islam moderat adalah paham keagamaan yang sangat relevan dalam konteks keberagaman dalam segala aspek, baik agama, adat istiadat, suku, dan bangsa itu sendiri. Keragaman dalam pemahaman adalah sebuah hal yang wajar dan hal ini menunjukkan fakta sejarah Islam dari zaman ke zaman. Keragaman tersebut, salah satunya, disebabkan oleh dialektika antara teks dan realitas itu sendiri, dan cara pandang terhadap posisi akal dan wahyu dalam menyelesaikan satu masalah. ${ }^{13}$ Sehingga moderasi dalam perkembangan zaman harus dijadikan sebuah prinsip umat Islam dalam membentengi dirinya.. Afrizal Nur menyebutkan beberapa ciri-ciri Islam moderat sebagai berikut:

1. Tawassuth (mengambil jalan tengah), yaitu pemahaman dan pengamalan yang tidak ifrath (berlebih-lebihan dalam beragama) dan tafrith (mengurangi ajaran agama).

2. Tawazun (berkeseimbangan), yaitu pemahaman dan pengamalan secara seimbang yang meliputi semua aspek kehidupan, baik duniawi maupun ukhrawi, tegas dalam menyatakan prinsip yang dapat membedakan antara inhiraf (penyimpangan) dan ikhtilaf (perbedaan).

3. I'tidal (lurus dan tegas), yaitu menempatkan sesuatu pada tempatnya dan melaksanakan hak dan memenuhi kewajiban secara proporsional.

4. Tasamuh (toleransi), yaitu mengakui dan menghormati perbedaan, baik dalam aspek keagamaan dan berbagai aspek kehidupan lainnya.

5. Musawah (egaliter), yaitu tidak bersikap diskriminatif pada yang lain disebabkan perbedaan keyakinan, tradisi dan asal usul seseorang.

6. Syura (musyawarah), yaitu setiap persoalan diselesaikan dengan jalan musyawarah untuk mencapai mufakat dengan prinsip menempatkan kemaslahatan di atas segalanya.

7. Ishlah (refirmsi) yaitu mengutamakan prinsip reformatif untuk mencapai keadaan lebih baik yang mengakomodasi perubahan dan kemajuan zaman dengan berpijak pada kemaslahatan umum (mashlahah 'ammah) dengan tetap berpegang pada prinsip al-muhafazhah 'ala al-qadimi alshalih wa al-akhdzu bi al-jadidi al-ashlah (melestarikan tradisi lama yang masih relevan, dan menerapkan hal-hal baru yang lebih relevan). 
8. Aulawiyah (mendahulukan yang prioritas), yaitu kemampuan mengidentifikasi hal ihwal yang lebih penting harus diutamakan untuk diimplementasikan dibandingkan dengan yang kepentingannya lebih rendah.

9. Tathawwir wa Ibtikar (dinamis dan inovatif), yaitu selalu terbuka untuk melakukan perubahan-perubahan sesuai dengan perkembangan zaman serta menciptakan hal baru untuk krmaslahatan dan kemajuan umat manusia.

10. Tahadhdhur (berkeadaban), yaitu menjunjung tinggi akhlak mulia, karakter, identitas, dan integritas sebagai khairu ummah dalam kehidupan kemanusiaan dan peradaban. ${ }^{14}$

\section{Latar Historis munculnya Radikalisme Agama di Indonesia}

Runtuhnya orde baru dan lahirnya era reformasi telah membawa perubahan pesat dalam tatanan kehidupan sosial masyarakat Indonesia. Gelombang wacana Radikalisme yang selalu disandingkan dengan aksi terorisme telah menjadikan Indonesia sebagai ladang pertarungan, baik pada level ide maupun aksi. ${ }^{15} \mathrm{Hal}$ ini dapat dilihat dalam keberagaman dari jumlah organisasi keislaman dan kelompok yang mengatasnamakan Islam sebagai kedok dalam kepentingannya. ${ }^{16}$ Sebagai bukti, datangnya gerakan-gerakan baru dari Islam yang berhaluan radikalisme. ${ }^{17}$

Akar kata radikalisme sendiri berasal dari kata radikal yang artinya besar-besaran dan menyeluruh, keras, kokoh, maju dan tajam (dalam berpikir). Biasanya seringkali didefinisikan sebagai faham politik kenegaraan yang menghendaki adanya perubahan dan perombakan sebagai jalan dalam memajukan negara. ${ }^{18}$ Menurut Wikipedia adalah suatu pemahaman yang dibuat-buat oleh sekelompok orang yang menginginkan perubahan atau pembaruan dari segi politik dan sosial secara siginifikan dengan menggunakan cara kekerasan. ${ }^{19}$ Menurut Harun Nasution, Radikalisme diartikan sebagai gerakan yang berpandangan kolot dan sering menggunakan kekerasan dalam mengajarkan keyakinan mereka. ${ }^{20}$ Sementara menurut Thalib, radikalisme diartikan sebagai Islam yang menunjuk berbagai gerakan Islam menggunakan berbagai bentuk kekerasan dalam rangka perjuangan untuk mendirikan negara Islam. ${ }^{21}$ Sehingga bisa disimpulkan bahwa radikalisme Islam adalah sebuah gerakan berbasis Islam yang di maksudkan untuk melakukan pembaruan dalam masalah sosial, politik, atau keagamaan yang dilakukan dengan cara drastis, keras, dan tanpa kompromi kepada pihak-pihak yaang tidak 
sesuai dengan prinsipnya yang dimana bahwa hanya syariat Islam yang mampu mengatasinya, sehingga pendirian negara Islam dan penerapan Syariat Islam menjadi ide perjuangannya.

Radikalisme kerap kali dihubungkan dengan konsep agama yang kemudian itu disebut dengan radikalisme agama, sehingga menjadi persoalan yang berhubungan dengan pengalaman inti, memori kolektif dan penafsiran agama. ${ }^{22}$ Peristiwa demi peristiwa yang ditengarai sebagai praktik dari paham radikalisme yang berakar pada rasa fanatisme juga kian mewarnai wajah berita Indonesia. Radikalisme yang semakin berkembang di wilayah masyarakat bukan pada pelajaran agama, melainkan pada bagaimana pelajaran tersebut di sampaikan. Banyak kisah tentang pelajaran agama yang dijadikan alat pencuci otak sejak masih kanak-kanak oleh para guru agama, pemuka agama, atau pengkhotbah yang beredar di masyarakat. ${ }^{23}$ Perspektif seseorang dalam berpandangan berbeda-berbeda, sehingga menimbulakan pemahaman yang berbeda-beda pula.

Pemahaman Islam yang radikal ini telah berkembang menjadi salah satu kelompok gerakan Islam baru yang membuat ricuh di kalangan masyarakat Islam dan membuat wajah Islam menjadi buruk, seperti kasus pengeboman 3 gereja di Surabaya, Jawa Timur. Kasus pengeboman yang terjadi hampir bersamaan ditiga Grejadi Surabaya yaitu Santa Maria J1 Ngagel Madya pukul 07.15 WIB, kemudian GKI di j1 Diponegoro 07.45 WIB dan GPPS J1 Arjuno 07.50 WIB Minggu 13 Mei 2018 kemaren menjadi tantangan dan catatan penting bagi Islam Indonesia, walaupun tidak semua sepakat bahwa kasus tersebut berhubungan dengan Islam, tetapi semua sepakat bahwa adanya teroris dan radikalisme adalah berawal dari adanya pemahaman dan pemikiran tentang teks agama secara tekstual. ${ }^{24}$

Dalam hal ini, gerakan radikalisme di Indonesia sering disandingkan dengan agama yang dalam beberapa kasus mengakibatkan tereduksinya eksistensi agama itu sendiri. Sehingga agama dalam kerangka ini menjadi "tertuduh" oleh stigma negatif radikalisme. ${ }^{25}$ Adanya sebuah konflik yang terjadi di Indonesia yang mengatasnamakan Islam, tidak dibenarkan oleh ajaran Islam yang sebenarnya. Agama yang hadir di Indonesia dalam praktiknya bersenyawa dengan kebudayaan di Indonesia. Saat Islam pertama kali muncul di Arab, maka Islam bertemu dengan agama hasil perpaduan antara tradisi Kristen-Yahudi di satu pihak dan di pihak lain merupakan gabungan tradisi Persia-Arab. Dalam pandangan kalangan Islam kultural, Islam Arab tidak bisa di universalkan di bumi Indonesia, selalu proses Islamisasi mengalami akulturasi kebudayaan atau nilai-nilai 
adat istiadat di masyarakat setempat. Semangat membumikan Islam tentu berbeda dengan semangat Arabisasi. ${ }^{26}$

Hal tersebut membuktikan bahwa Islam yang di ajarkan adalah Islam yang penuh dengan kedamaian dan seimbang, bukan condong ke kanan maupun condong kekiri. Sikap perdamaian dan persaudaraan dalam menghargai hak-hak asasi manusia harus ditegakkan untuk mencapai persatuan dan kesatuan umat manusia. Sebab persatuan yang kuat akan menimbulkan sebuah kekuatan dan menghindarkan dari kehinaan dan kelemahan. Agama Islam sangat menjunjung tinggi perdamaian dan kemanusiaan dalam rangka menjalin Ukhuwah Islamiah dan mencegah dari permusuhan, hal ini menunjukkan bahwa perdamaian adalah ruh dari Islam. ${ }^{27}$ Karena pada dasarnya ajaran Islam sendiri mengarah kepada tercapainya prinsip Maqasidus Syariah (tujuan syariat islam), yaitu menjaga agama, jiwa, akal, harta dan keturunan. ${ }^{28}$ Sehingga menjadikan permasalahan-permasalahan yang terjadi dapat terselesaikan dari prinsip perdamaian Islam di Indonesia.

\section{Formulasi konsep Moderasi Islam berbasis Keindonesiaan (Upaya Mereduksi Radikalisme Agama di Indonesia)}

Berbicara mengenai Islam di Indonesia, bahwa Islam dalam dataran dunia secara makro mengalami perkembangan yang pesat, di mana umat Islam sudah tersekat oleh batas-batas negara, etnik dan geografis. Sehingga hukum Islam-pun, baik secara konsepsional maupun praksisknya dituntut untuk menemukan formulasi yang sesuai dengan habitatnya. ${ }^{29}$ Karena Indonesia bukanlah negara Islam, melainkan negara yang mayoritas penduduknya muslim. Sehingga relasi agama dan negara adalah bersifat simbiotik.

Dalam konteks ini, maka masih perlunya diformulasikan model artikulasi hukum Islam yang tepat dalam wacana kebangsaan dan kenegaraan. Seperti kesamaan cita-cita yaitu menginginkan format fikih baru yang sesuai dengan realitas keindonesiaan.

Para teoritikus Fikih Siyasah, semisal, al-Juwaini, a-Ghazali, alMawardi, dan lain sebagainya, menetapkan tujuan negara sebagai institusi yang bertujuan untuk harasati ad-dini (memelihara agama), dan siyati al-dunya (mengelola negara) dalam rangka menerapkan syariat Islam, menolak kerusakan, mewujudkan kemaslahatan umum, menegakkan keadilan dan menggapai kesejahteraan dan kemakmuran lahir-batin, dunia-akhirat. Sementara soal bentuk pemerintahan, bukan yang esensial dari pendirian 
negara. Yang esensial adalah tujuan negara, bukan bentuk pemerintahan. Sebab, bentuk pemerintahan itu sekadar sarana untuk mencapai tujuan negara. Sistem demokrasi adalah sarana, bukanlah tujuan ${ }^{30}$

Sehingga karakter Islam yang harus dibangun di Indonesia adalah Islam yang akomodatif. Yaitu Islam yang ramah dengan tradisi, pandangan tersebut dikenal dengan istilah al muhafadzah ala al-qadim al-shalih wa alakhzdu bi al-jadid al-ashlah.

Upaya inilah yang dapat mereduksi radikalisme agama di Indonesia. Sebab dengan tidak meninggalkan tradisi yang baik dan mengambil tradisi yang dianggap baik akan menjadi bentengi umat Islam dari radikalisme.

\section{Simpulan}

Secara historis kedatangan Islam di Indonesia dilakukan secara damai, hal tersebut tentunya berbeda dengan penyebaran Islam di Timur Tengah yang beberapa kasus disertai dengan penundukan wilayah oleh militer muslim. Sedangkan Moderasi Islam adalah sebuah pandangan atau sikap yang selalu berusaha mengambil posisi tengah dari dua sikap yang berseberangan dan berlebihan sehingga salah satu dari kedua sikap yang dimaksud tidak mendominasi dalam pikiran dan sikap seseorang. Afrizal Nur menyebutkan beberapa ciri-ciri Islam moderat sebagai berikut: Tawassuth (mengambil jalan tengah), Tawazun (berkeseimbangan), I'tidal, Tasamuh (toleransi), Musawah (egaliter), Syura (musyawarah), Ishlah (refirmsi) Aulawiyah (mendahulukan yang prioritas), Tathawwir wa Ibtikar (dinamis dan inovatif), Tahadhdhur (berkeadaban).

Gerakan radikalisme di Indonesia sering disandingkan dengan agama yang dalam beberapa kasus mengakibatkan tereduksinya eksistensi agama itu sendiri. Sehingga agma dalam kerangka ini menjadi "tertuduh" oleh stigma negatif radikalisme. Dalam konteks ini, maka formulasi model artikulasi hukum Islam yang tepat dalam wacana kebangsaan dan kenegaraan. Seperti kesamaan cita-cita yaitu menginginkan format fikih baru yang sesuai dengan realitas keindonesiaan. Yaitu Islam yang ramah dengan tradisi, pandangan tersebut dikenal dengan istilah al muhafadzah ala al-qadim al-shalih wa al-akhzdu bi al-jadid al-ashlah. Upaya inilah yang dapat mereduksi radikalisme agama di Indonesia. Sebab dengan tidak meninggalkan tradisi yang baik dan mengambil tradisi yang dianggap baik akan menjadi bentengi umat Islam dari radikalisme 


\section{Endnotes}

1 Lihat dalam Musyrifah Sunanto, Sejarah Peradaban Islam Indonesia, (Jakarta: PT Raja Grafindo Persada, 2014), hlm 3. Lihat juga dalam Rizem Aidid, Sejarah Islam Nusantara, (Yogyakarta: Diva Press, 20160,) hlm 16.

2 Ibid., hlm 8.

3 Musyrifah Sunanto, Sejarah Peradaban Islam Indonesia, (Jakarta: PT Raja Grafindo Persada, 2014) hlm 22.

4 Zakiya Darajat, "Muhammadiyah dan NU: Penjaga Moderatisme Islam di Indonesia", Hayula : Indonesian Journal of Multidiciplinary Islamic Studies, Vol 1 No. 1 (Januari, 2017), hhlm 81.

5 Rizem Aizid, Sejarah Islam Nusantara, (Yogyakarta : Diva Press 2016), hlm 33-41

6 Q.S. Al-Maidah Ayat 3.

7 Muhaimin dkk, Studi Islam dalam Ragam Dimensi \& Pendekatan, (Jakarta : Kencana, 2005), hlm 8.

8 https://kbbi.kemdikbud.go.id/entri/moderasi

9 Moh Ali Wasik, Islam Agama Semua Nabi dalam Perspektif Al-Quran, Esensia, Vol 17 No. 2 (Maret, 2016), hlm. 227.

10 Abd. Rauf Muhammad Amin, Prinsip dan Fenomena Moderasi Islam dalam Tradisi Hukum Islam, Jurnal "Al-Qalam", Volume 20, Edisi khusus Desember 2014, hlm. 24.

11 Q.S. Al-Baqarah 143.

12 Achmad Yusuf, Moderasi Islam dalam Dimensi Trilogi Islam (Akidah, Syariah, dan Tasawuf), Jurnal Pendidikan Agama Islam, Volume 3, Nomor 2, Juni 2018, hlm. 204.

13 Darlis, Mengusung Moderasi Islam di Tengah Masyarakat Multikultural, Jurnal Rausyan Fikr, Vol. 13, No. 2, Desember 2017, hlm. 231.

14 Afrizal Nur, Konsep Washathiyah dalam Al-Qur'an; (Studi Komparatif Antara Tafsir AlTahrir Wa At-Tanwir dan Aisar At-Tafasir, An-nur, Vol. 4 No. 2, 2015, hlm. 212.

15 Abdul Mukti Ro'uf, Mengurai Radikalisme Agama di Indonesia Pasca Orde Baru, Ulumuna, Vol. 9, No. 1 Juni 2017, hlm. 158.

16 Sun Choirol Ummah, Akar Radikalisme Islam di Indonesia, Humanika, No. 12, September 2012, hlm. 117.

17 Abdul Mukti Ro'uf, Mengurai Radikalisme Agama di Indonesia Pasca Orde Baru, Jurnal Ulumuna, Volume XI, Nomor 1, Juni 2007, hlm. 157.

18 Saifuddin, Radikalisme Islam di Kalangan Mahasiswa (Sebuah Metaamorfosa Baru), Analisis, Volume XI, Nomor 1, Juni 2011, hlm. 18-19.

19 A Faiz Yunus, Radikalisme, Liberalisme dan Terorisme; Pengaruhnya Terhadap Agama Islam, Jurnal Studi Al-Qur'an, Vol. 13, No. 1, Tahun 2017, hlm. 80.

20 Harun Nasution, Islam Rasional, (Bandung: Mizan, 1995), hlm. 124.

21 Nurjannah, Faktor Pemicu Munculnya Radikalisme Islam Atas Nama Dakwah, Jurnal Dakwah, Vol. XIV, No. 2 Tahun 2013, hlm. 180.

22 Zuhdi, Radikalisme Agama dan Upaya Deradikalisasi Pemahaman Keagamaan, AKADEMIKA: Jurnal Pemikiran Islam, Volume 22, No. 01, Januari-Juni 2017, hlm. 199.

23 Hayatmoko, Etika Politik dan Kekuasaan, (Jakarta: Kompas, 2014), hlm. 113-114.

24 Muhammad Hisbullah, Dakwah Harakah, Radikalisme dan Tantangannya di Indonesia, Misykat Al-Anwar, Vol. 9, No. 2 Tahun 2018, hlm. 14.

25 Abdul Mukti Ro'uf, Mengurai Radikalisme Agama di Indonesia Pasca Orde Baru, Jurnal Ulumuna, Volume XI, Nomor 1, Juni 2007, hlm. 159.

26 Khoirurrijal, Islam Nusantara Sebagai Counter Hegemoni Melawan Radikalisme Agama di Indonesia, AKADEMIKA, Vol. 22, No. 01, Januari-Juni 2017, hlm. 84.

27 Supriyanto, Perdamaian dan Kemanusiaan dalam Pandangan Islam, Jurnal Studi Agama dan Pemikiran Islam, Volume 7, Nomor 2, Desember 2015, hlm. 308.

28 Jamal Ma'mur Asmani, Rekontruksi Teologi Radikalisme di Indonesia, Menuju Islam Rahmatan Lil Alamin, Wahana Akademika, Vol. 4, No 1, April 2017, hlm 13.

29 Masnun Tahir, Wacana Fikih Kebangsaan dalam Penanggulangan dan Pencegahan Radikalisme di Lingkungan Kampus di NTB, As-Syariah, Vol. 49. No 2, Desember 2015, hlm 307

30 Ibid, hlm 307 


\section{DAFTAR PUSTAKA}

Aidid, Rizem. 2016. Sejarah Islam Nusantara. Yogyakarta: Diva Press.

Asrori, Ahmad. Radikalisme di Indonesia (Antara Historisitas dan Antropisitas), Jurnal Studi Agama dan Pemikiran Islam. Volume 9. Nomor 2.

Choirul Ummah, Sun. 2012. Akar Radikalisme Islam di Indonesia. Humanika, No. 12.

Darajat, Zakiya. 2017. Muhammadiyah dan NU. Hayula: Indonesian Journal of Multidiciplinary Islamic Studies, Vol 1 No. 1.

Darlis. 2017. Mengusung Moderasi Islam di Tengah Masyarakat Multikultural. Jurnal Rausyan Fikr. Vol. 13. No. 2.

Hayatmoko. 2014. Etika Politik dan Kekuasaan. Jakarta: Kompas.

Hisbullah. Muhammad. 2018. Dakwah Harakah, Radikalisme dan Tantangannya di Indonesia. Misykat Al-Anwar, Vol. 9, No. 2.

Khoirurrijal. 2017. Islam Nusantara Sebagai Counter Hegemoni Melawan Radikalisme Agama di Indonesia. AKADEMIKA. Vol. 22. No. 01.

Muhaimin. 2005. Studi Islam dalam Ragam Dimensi \& Pendekatan. Jakarta: Kencana.

Muhammad Amin, Abd. Rauf. 2014. Prinsip dan Fenomena Moderasi Islam dalam Tradisi Hukum Islam. Jurnal "Al-Qalam”. Volume 20.

Mukti Ro'uf, Abdul. 2017. Mengurai Radikalisme Agama di Indonesia Pasca Orde Baru. Ulumuna. Vol. 9, No. 1.

Nasution, Harun. 1995. Islam Rasional. Bandung: Mizan.

Nur, Afrizal. 2015. Konsep Washathiyah dalam Al-Qur'an; (Studi Komparatif antara Tafsir Al-Tahrir wa At-Tanwir dan Aisar At-Tafasir. An-nur. Vol. 4 No. 2.

Sunanto, Musyrifah. 2014. Sejarah Peradaban Islam Indonesia. Jakarta: PT Raja Grafindo.

Supriyanto. 2015. Perdamaian dan Kemanusiaan dalam Pandangan Islam. Jurnal Studi Agama dan Pemikiran Islam. Volume 7. Nomor 2.

Tahir, Masnun. 2015. Wacana Fikih Kebangsaan dalam Penanggulangan dan Pencegahan Radikalisme di Lingkungan Kampus di NTB, AsSyariah, Vol. 49. No 2. 
Wasik, Moh Ali. 2016. Islam Agama Semua Nabi dalam Perspektuf AlQur'an. Esensia. Vol 17 No. 2.

Yusuf, Achmad. 2018. Moderasi Islam dalam Dimensi Trilogi Islam (Akidah, Syariah, dan Tasawuf). Jurnal Pendidikan Agama Islam. Volume 3. Nomor 2.

Zuhdi. 2017. Radikalisme Agama dan Upaya Deradikalisasi Pemahaman Keagamaan. AKADEMIKA: Jurnal Pemikiran Islam. Volume 22. No. 01. 